\title{
School oral health survey in Kairouan, Tunisia
}

F. Maatouk, A. Ameur, ${ }^{2}$ H. Ghedira, ${ }^{3}$ B. Belgacem ${ }^{4}$ and D. Bourgeois ${ }^{5}$

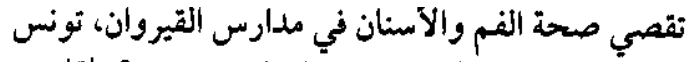

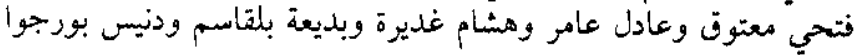

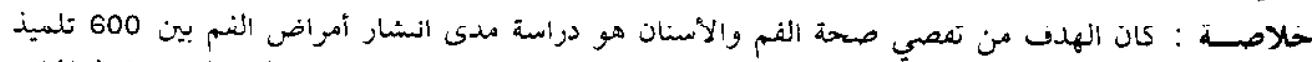

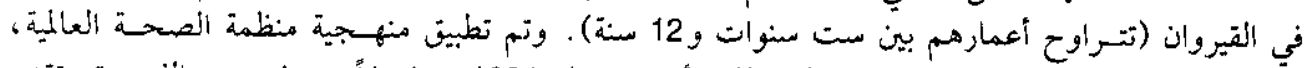

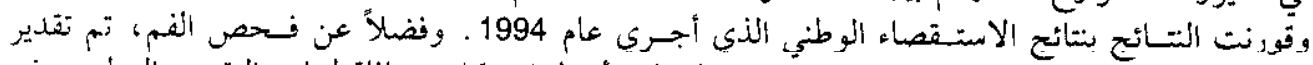

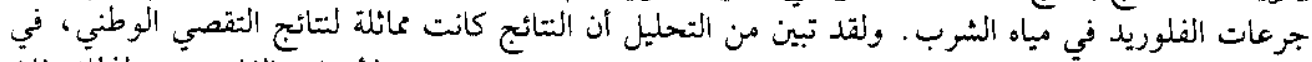

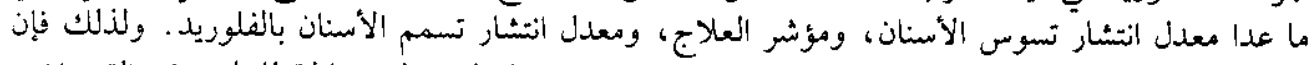

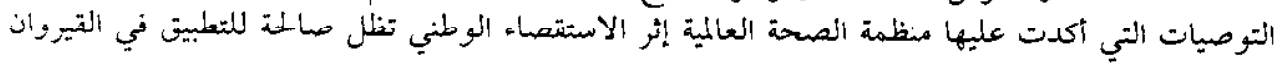

ABSTRACT The aim of the oral health survey was to study oral disease prevalence in 600 schoolchildren (aged 6 years and 12 years) in Kairouan. World Hoalth Organization methodology was used and the results were compared with the 1994 national survey findings. As well as oral examination, fluoride dosage in drinking water was assessed. Analysis showed that the findings were in agreement with the national survey except for dental caries prevalence. therapeutic index and dental fluorosis prevalence. Thus WHO recommendations made after the national survey remain valid in Kairouan.

\section{Enquete sur la santé bucco-dentaire dans les écoles à Kairouan (Tunisie)}

RESUME Une enquête sur la santé bucco-dentaire a été réalisée pour étudier la prévalence des affections bucco-dentaires chez 600 enfants âgés de 6 et 12 ans à Kairouan (Tunisie). La méthodologic préconisée par l'Organisation mondiale de la Santé a été utilisée et les résultats ont été comparés avec ceux de l'enquête nationale de 1994. Outre l'examen bucco-dentaire, un dosage a été effectué pour évaluer la teneur de l'eau de boisson en fluor. L'analyse a montré que les résultats étaient conformes à l'enquête nationale sauf pour la próvalence des caries dentaire, l'indice des besoins en matière de traitement et la prévalence de la fluorose dentaire. Les recommandations de l'OMS formulées suite à l'enquête nationale demeurent donc valables à Kairouan.

\footnotetext{
'Professor; ${ }^{3}$ Assistant Professor, Department of Paedodontics, Dental School, University of Monastir, Monastir, Tunisia.

'Dentist, Ksar Hollal, Tunisia.

${ }^{4}$ Physician, School Health Department, Tunis, Tunisia.

sOral Health Unit, WHO, Geneva, and Professor, Dental School, University of Lyon, Lyon, France.
Received: 07/10/96; accopted: 11/02/07
} 


\section{Introduction}

In Tunisia, $47 \%$ of the population are under 20 years of age and authorities follow students' health with particular interest. In 1994 , a third national oral health survey in schools was conducted by the Ministry of Health using World Health Organization (WHO) methodology [1]. This cross-sectional survey, which covered 1802 schoolchildren aged 6,12 and 15 years, revealed that:

- Dental caries prevalence was $57 \%, 48 \%$ and $58 \%$ at 6,12 and 15 years respectively.

- Decayed, missing and filled (DMF) teeth scores were about 1.3 at 12 years and 2.01 at 15 years with a very low $F$ component.

- $44 \%$ of children at 12 years and $60 \%$ at 15 years had calculus.

The aims of the present study, which was conducted in Kairouan, were:

- to determine the prevalences of different oral diseases in schoolchildren in this region and to compare them with the national survey results;

- to verify if fluorosis prevalence had really decreased in this area as shown by the national survey.

\section{Subjects and methods}

A total of 600 schoolchildren, 294 females and 306 males, were randomly chosen by stratified random sampling with adjustment to age. The target ages were 6 years and 12 years. Training of six dental students as examiners and calibration and standardization of examining techniques are dealt with in the oral health surveys manual [2].

After making contact with the authorities and obtaining the necessary authoriza- tion, a clinical examination to detect oral diseases was carried out in the classroom using usual dental examining instruments. The simplified WHO form (1986) was used to record information [3]; tea drinking and toothbrush possession were also recorded. Dental caries lesions were recorded according to WHO criteria. Periodontal diseases and dental fluorosis were detected only in permanent dentition (12-year-old children) because such lesions in primary dentition are reported to be rare [3]. Samples of drinking water were collected in plastic bottles from each borough of Kairouan and refrigerated as recommended by WHO. Fluoride concentration was then assessed using a specific fluoride electrode technique. Educational materials to promote oral health were distributed to schoolchildren and teachers.

WHO had approved the survey protocol and kindly analysed our data. The usual indices for evaluation of dental caries (DMF) and periodontal diseases, community periodontal index for treatment needs (CPITN), were calculated. The chi-squared test was used to compare different percentages with the $5 \%$ level of significance.

\section{Results and analysis}

The composition of the sample by age, sex and residence is shown in Table 1. It should be noted that $60 \%$ of the children were from a modest socioeconomic level.

Our analysis showed that among oral diseases, periodontal diseases were significantly high, indeed their prevalence was about $57 \%$ in 12-year-old schoolchildren in Kairouan versus $60 \%$ in the national survey (Table 2). It should be noted that, on average, each child with periodontal problems had trouble in 2.3 sextants (Table 2). 
Table 1 Distribution of schoolchildren by age, sex and residence

\begin{tabular}{lccccc}
\hline $\begin{array}{l}\text { Age } \\
\text { (years) }\end{array}$ & No. & Male & Female & $\begin{array}{c}\text { Urban } \\
\text { area } \\
\%\end{array}$ & $\begin{array}{c}\text { Rural } \\
\text { area } \\
\%\end{array}$ \\
\hline 6 & 300 & 49.3 & 50.7 & 29.3 & 70.7 \\
12 & 300 & 52.7 & 47.4 & 62.3 & 37.0 \\
Total & 600 & 51.0 & 49.0 & 45.8 & 53.8 \\
\hline
\end{tabular}

in $0.7 \%$ of 12 yearolds the area of residence was undeterminod

Table 2 Periodontal status in 12 year-olds

\begin{tabular}{lccc}
\hline & $\begin{array}{c}\text { Bleeding } \\
\%\end{array}$ & $\begin{array}{c}\text { Calculus } \\
\%\end{array}$ & $\begin{array}{c}\text { Total } \\
\%\end{array}$ \\
\hline $\begin{array}{l}\text { Our study } \\
(n=300)\end{array}$ & $6.7\left(1.3^{\mathrm{a}}\right)$ & $50.0\left(1.0^{\mathrm{a}}\right)$ & 56.7 \\
$\begin{array}{c}\text { National survey } \\
(n=602)\end{array}$ & 16.5 & 44.0 & 60.5 \\
\hline number of sextants & &
\end{tabular}

Table 3 Prevalence (\%) of dental caries by age and sex compared with the nationai survey

\begin{tabular}{|c|c|c|c|c|}
\hline \multirow{2}{*}{$\begin{array}{l}\text { Age } \\
\text { (years) }\end{array}$} & \multicolumn{3}{|c|}{ Our study } & \multirow{2}{*}{$\begin{array}{c}\text { National } \\
\text { survey } \\
\text { Total }\end{array}$} \\
\hline & Male & Female & Total & \\
\hline 6 & 56.8 & 17.4 & 52.1 & 56.7 \\
\hline 12 & 31.0 & 36.6 & 33.8 & 48.3 \\
\hline Total & 43.9 & 42.0 & $42.9^{*}$ & $52.5^{*}$ \\
\hline
\end{tabular}

With regard to periodontal treatment needs, $56.7 \%$ of the schoolchildren required oral hygiene instruction (CPITN1) and $50.0 \%$ required scaling (CPITN2). None required more complex treatment (CPITN3).

The results show a remarkably high prevalence of dental caries in primary teeth $(52 \%)$, much higher than in permanent teeth (34\%) (Table 3 ). The same observations were made in the national survey but with higher prevalence $(P<0.001)$. There was no significant difference between the prevalence of caries in males and females.

Our results also showed a mean dmf index of 1.71 at 6 years with a high d component, while the f component, a conservative care indicator, was very low; 0.02 out of 1.71 , i.e. only one primary tooth was filled for 85 decayed teeth (Table 4). DMF was about 0.8 at 12 years, lower than the national mean DMF which was about 1.3 and also lower than WHO goals for the year 2000 for the world (DMF $=3$ ) and for countries of the Eastern Mediterranean Region (EMR) $(\mathrm{DMF}=1.5)$ [4]. Again the D component was very high $(0.77)$ while the $F$ component was low (one permanent tooth filled for 40 decayed teeth). In fact, $\mathrm{d}$ and $\mathrm{D}$ components were lower than the national mean.

Nearly half of the children aged 6 years (49.5\%) needed care (obturation) on primary teeth; at 12 years, $33 \%$ required such treatment. In addition, $8.0 \%$ aged 6 years and $3.0 \%$ aged 12 years required extrac-

Table 4 Mean $\mathrm{dmf}$ and DMF indices compared with the national survey

\begin{tabular}{|c|c|c|c|c|c|c|c|c|}
\hline & \multicolumn{4}{|c|}{6 years } & \multicolumn{4}{|c|}{12 years } \\
\hline & d & $m$ & $\uparrow$ & $d m f$ & D & $M$ & $\mathbf{F}$ & DMF \\
\hline Our study & 1.66 & 0.03 & 0.02 & 1.71 & 0.77 & 0.01 & 0.02 & 0.8 \\
\hline National survey & 1.97 & 0.13 & 0.03 & 2.12 & 1.18 & 0.07 & 0.05 & 1.3 \\
\hline
\end{tabular}


Table 5 Prevalence of fluorosis and fluoride dosage in some areas of Kairouan

\begin{tabular}{lcc}
\hline Area & $\begin{array}{c}\text { Fluorosis } \\
(\%)\end{array}$ & $\begin{array}{c}\text { Dosage } \\
(\mathrm{ppm})\end{array}$ \\
\hline A & 6.0 & 1.19 \\
B & 10.4 & 1.35 \\
C & 72.0 & 2.23 \\
D & 73.0 & 0.40 \\
E & 98.0 & 2.80 \\
\hline
\end{tabular}

Table 6 Toothbrush possession and tea drinking among the children surveyed

\begin{tabular}{lcccc}
\hline \multirow{2}{*}{$\begin{array}{l}\text { Age } \\
\text { (years) }\end{array}$} & \multicolumn{2}{c}{$\begin{array}{c}\text { Possess a } \\
\text { toothbrush }\end{array}$} & \multicolumn{2}{c}{ Drink tea } \\
& No. & $\%$ & No. & $\%$ \\
\hline 6 & 69 & 23.0 & 28 & 09.3 \\
12 & 215 & 71.7 & 61 & 17.0 \\
Total & 284 & 47.3 & 79 & 13.2 \\
\hline
\end{tabular}

tion, and $4.0 \%$ aged 6 years and $1.3 \%$ aged 12 years required other dental treatment, such as pulpal treatment and prosthesis. However, it should be noted that the WHO treatment codification used is simply indicative and it is difficult in survey conditions to establish a precise diagnosis.

In our study, $30 \%$ of 12 year-olds had malocclusion compared with $38 \%$ in the national survey; $18.7 \%$ had mild malocclusion and $11.3 \%$ had moderate to severe malocclusion compared with $26.0 \%$ and $11.7 \%$ in the national survey respectively. It is the highest percentage reported in the countries of the EMR.

Analysis of previous studies revealed the following prevalence of dental fluorosis in Kairouan: 1988, 33.6\%; 1994 (national survey) $12.0 \%$; 1995 (our study) $57.7 \%$. The prevalence of 1994 seems unrealisti- cally low. This comparison confirms that Kairouan is an area of endemic fluorosis with a prevalence of $57.7 \%$ in 12-year-old schoolchildren (lable 5). The distribution of dental fluorosis in Kairouan according to the Dean index was $11.0 \%$ (code 1 ), $15.0 \%$ (code 2), 13.3\% (code 3 ) and $18.4 \%$ (code 4); there were no cases of code 5 fluorosis. Fluorosis prevalence increased with increased fluoride dosage in drinking water (Table 5) except in area D where fluoride concentration was low but fluorosis was $73 \%$. Children in this area may drink well water rather than tap water and may be exposed to fluoride in fruit, vegetables and tea.

Regarding toothbrush possession, prevalence was higher at the age of 12 years $(71.7 \%)$ than at the age of 6 years $(23 \%)$ (Table 6). These percentages were overestimated, especially in 12 year-olds, because of misreporting by the children. The findings revealed that the percentage of children who drank tea (13.2\%) was almost the same as the national average (15\%) (Table 6). Tea, which is very rich in fluoride, is a popular drink in Tunisia.

\section{Discussion}

Dental caries was relatively frequent in schoolchildren in Kairouan despite the high prevalence of toothbrush possession, which was undoubtedly overestimated. The findings reflect a great insufficiency in treatment of caries both in primary and permanent teeth. Children and parents should be encouraged to visit dentists more often. Furthermore, dentist-patient and dental unit-patient ratios must be improved [5]. Periodontal trouble (especially calculus) is a serious problem in 12-year-old schoolchildren in Kairouan, as it is at the national level. Authorities must take this into account in 
the National Preventive Oral Health Programme. This is also true for malocclusion, which is more frequent here than in other countries of the EMR. Dental fluorosis is endemic in some regions of Tunisia (e.g. Kairouan) as in other North African countries and this may decrease dental caries.

\section{Conclusion}

Our findings are in agreement with the national oral health survey except that the dental caries prevalence and the dental ther- apeutic index ( $\mathrm{F}$ component) were lower in Kairouan, and the fluorosis prevalence was higher. Thus, the WHO recommendations, given after the national survey, are valid for the Kairouan oral health situation, in particular the recommendations to:

- reduce dental caries prevalence to $40 \%$ in 6 year-olds

- keep DMF stable in 12 year-olds

- increase the $F$ component and reduce the $\mathrm{D}$ component in 12 year-olds

- reduce calculus prevalence to $22 \%$.

\section{Rererences}

1. National oral health survey. Tunisia, Ministry of Public Healtn, 1994.

2. A guide to oral health: epidemiological investigations. Geneva, World Health Organization, 1979 (unpublished document ORH/EPID. GUIDE/79.1; available on request from the Oral Health Unit, Division of Noncommunicable Diseases, World Health Organization, 1211 Geneva 27, Switzerland).

3. Oral health surveys. Basic methods, 3rd ed. Geneva, World Health Organization, 1987.
4. Oral health global indicators for 2000 . Dental caries level at 12 years. Baseline information booklet. Geneva, World Health Organization, 1990 (unpublished document WHO/OFH/DMFT/12.90; available on request from the Oral Health Unit, Division of Noncommunicable Diseases, World Health Organization, 1211 Geneva 27, Switzerland).

5. Research and action for the promotion of oral health within primary health care. Geneva, World Health Organization, 1988 (unpublished document No. WHO/ $\mathrm{ORH} / \mathrm{HSR}$. 88; available on request from the Oral Health Unit, Division of Noncommunicable Diseases, World Health Organization, 1211 Geneva 27, Switzerland). 